Abstracted/indexed in Academic Search Complete, Asia Journals Online, Bangladesh Journals Online, Biological Abstracts, BIOSIS Previews, CAB Abstracts, Current Abstracts, Directory of Open Access Journals, EMBASE/Excerpta Medica, Google Scholar, HINARI (WHO), International Pharmaceutical Abstracts, Open J-gate, Science Citation Index Expanded, SCOPUS and Social Sciences Citation Index;

ISSN: $1991-0088$

\title{
Grape seed and skin extract protects against acute chemotherapy toxicity induced by doxorubicin in rat red blood cells and plasma
}

\author{
Sonia Hamlaoui', Meherzia Mokni' ${ }^{1}$ Nadia Limam¹, Alice Carrier², Ferid Limam³, \\ Mohamed Amri' ${ }^{1}$, Lamjed Marzouki ${ }^{1}$ and Ezzedine Aouani3
}

${ }^{1}$ Laboratoire de Neurophysiologie Fonctionnelle et Pathologies, Département des Sciences Biologiques, Faculté des Sciences de Tunis. Campus Universitaire El Manar II-2092 Tunis, Tunisie; ' INSERM, U624 «Stress cellulaire» Case 915 Parc Scientifique de Luminy, 13288 Marseille Cedex 9, France; ' Laboratoire des Substances Bioactives, Centre de Biotechnologie, Technopole Borj-Cedria, BP-901, 2050 Hammam-Lif, Tunisie.

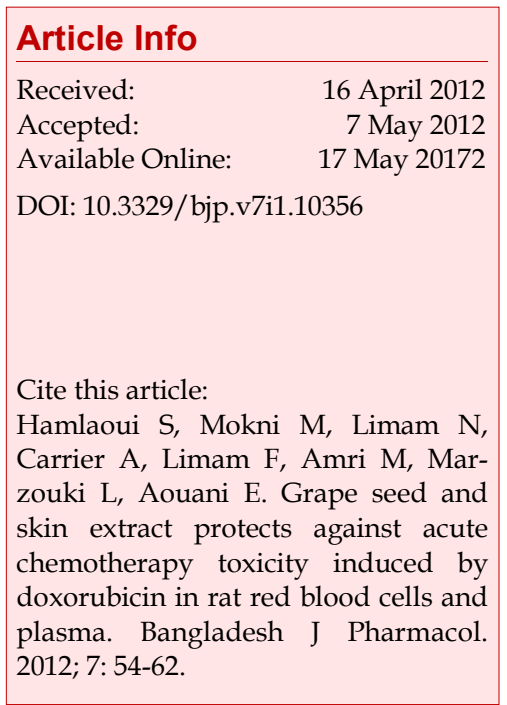

\begin{abstract}
In this study, the protective role of grape seed and skin extract (GSSE) against doxorubicin-induced blood toxicity has been evaluated in rats. Rats were treated with the extract for 8 days and injected with doxorubicin $(20 \mathrm{mg} / \mathrm{kg})$ at the 4th day. At the end of the treatment, blood samples were collected for oxidative stress parameters determination and anti-oxidant enzymes. Doxorubicin increased erythrocytes and plasma malondialdehyde, free iron, $\mathrm{H}_{2} \mathrm{O}_{2}$ and carbonylation, decreased calcium and also decreased erythrocytes catalase, peroxidase and superoxide dismutase (specially the Fe isoform). Doxorubicin also decreased plasma catalase and superoxide dismutase $(\mathrm{Cu} /$ $\mathrm{Zn}$ and Fe isoforms) but increased peroxidase. Doxorubicin increased plasma alanine aminotransferase and aspartate aminotransferase but decreased them within erythrocytes. GSSE co-treatment counteracted almost all deleterious effects induced by doxorubicin. In conclusion, doxorubicin induced a prooxidative stress into rat erythrocytes and plasma and GSSE exerted antioxidant properties which can be attributed to free iron and calcium modulation.
\end{abstract}

\section{Introduction}

Doxorubicin (Dox) (Adriamycin) has been used in oncologic practice since the late 1960s. It held promise as a powerful drug in the fight against cancer (Singal et al., 1998). However, the clinical efficacy of this drug is limited due to damages toxicity in adults and pediatric cancer patients (Buzdar et al., 1985). The exact causal mechanism of Dox induced toxicity remains unclear, but most of the evidence indicates that free radicals are involved (Singal et al., 1987; Sinha et al., 1987a). The chemical structure of Dox is prone to the generation of free radicals, (Sinha et al., 1987b) and the oxidative stress that results correlates with cellular injury (Rosen and Halpern, 1990). In addition, Dox administration is associated with a decrease in endogenous anti-oxidants responsible for the scavenging of free radicals (Singal et al., 1995) leading to increased oxidative stress, which is followed by damages in organism (Doroshow et al., 1980).

Grape seed and skin extract (GSSE) is a nutritional supplement exhibiting beneficial health effects (Suwannaphet et al., 2010). GSSE is a complex mixture of polyphenolics classified as flavonoid and non flavonoid compounds (Khanal et al., 2009). Flavonoids, which are highly concentrated in grape seeds are mainly composed of monomeric catechins, proanthocyanidins and flavonols, such as quercetin (Renaud and De Lorgeril, 1992). Non flavonoids, highly abundant in grape skin, 
contain stilbenes such as resveratrol, which is at the basis of the french paradox (Renaud and De Lorgeril, 1992). GSSE has wide-ranging benefits including cardioprotective (Decordé et al., 2009), renoprotective (Safa et al., 2010), and neuroprotective (Wang et al., 2009) effects. GSSE also protects against hepatic ischemia-reperfusion injury (Sehirli et al., 2008), biliary obstruction (Dulundu et al., 2007), and azathioprineinduced hepatotoxicity in rats (El-Ashmawy et al., 2010). More specifically, resveratrol is multi-organ protective owing to its anti-oxidant (Kelen and Tepe, 2007) and anti-inflammatory properties (Kowalczyk et al., 2010). Proanthocyanidins exert antineoplasic effects by inducing cytotoxicity towards some cancer cells (Chatelain et al., 2011), by cell cycle arrest and induction of apoptosis (Kaur et al., 2008). In addition quercetin and rutin are neuroprotective (Jimenez-Aliaga et al., 2011), and catechin, epicatechin, and gallic acid have exhibited cholesterol-lowering activity (Ngamukote et al., 2011).

In the present work, we evaluated the effect of an acute administration of Dox on oxidative stress induced in the blood compartment as well as the putative protection offered by GSSE. Dox induces a pro- oxidative state and GSSE exerts potent anti-oxidative properties by counteracting the Fenton reaction of $\mathrm{H}_{2} \mathrm{O}_{2}$ with free iron, leading to intracellular calcium dysregulation.

\section{Materials and Methods}

\section{Reagents}

2-thiobarbituric acid (TBA); 2,6,-di-tert-butyl-4-hydroxy -toluene (BHT); trichloroacetic acid (TCA); hydrogen peroxide $\left(\mathrm{H}_{2} \mathrm{O}_{2}\right) ;$ 2-methoxyphenol (gaiacol); bovine catalase and 4-(1-Hydroxy-2-methylamino-ethyl)-benzene-1,2-diol (epinephrine), 2,4,dinitrophenyl hydrazine (DNPH) were obtained from Sigma-Aldrich (Germany). Doxorubicin hydrochloride was purchased from Pharmacia Italia (Italy).

\section{Preparation of grape seed and skin extract}

GSSE was processed from a grape cultivar (Carignan) of Vitis vinifera from northern Tunisia. Waste from winemaking was collected from Tardi Cooperative Winery (Ain Ghelal). Seeds and skin were dried and ground separately with an electric mincer (FP3121 Moulinex) until a fine powder was obtained. Total phenolic content was determined by the folinCiocalteau colorimetric method (Singleton and Rossi, 1965), flavonoids and condensed tannins according to Dewanto et al. (2002) and Sun et al. (1998) respectively (Table I). Powder mixture containing grape seed (50\%) and skin $(50 \%)$ was dissolved in $1 \mathrm{~mL}$ of $10 \%$ ethanol in the dark, vigorously vortexed for $10 \mathrm{~min}$, centrifuged at $10,000 \mathrm{~g}$ for $15 \mathrm{~min}$ at $4^{\circ} \mathrm{C}$ for debris elimination and the supernatant containing soluble polyphenols was used.

\section{Animals and treatment}

Female Wistar rats (220-40 g) were used in these experiments in accordance with the ethic committee of Tunis University for care and use of animals in conformity with NIH guideline (NIH, 1985). They were provided with food and water ad libitum and maintained in animal facility at fixed temperature of 22 $\pm 2^{\circ} \mathrm{C}$ with a 12 hours light-dark cycle. Rats were randomly divided into four groups of six animals each and daily intraperitoneally injected with either vehicle (C: $10 \%$ ethanol) or GSSE (500 mg/ $\mathrm{kg} \mathrm{bw}$ ) for 8 days. Dox was dissolved in saline and administered at 20 $\mathrm{mg} / \mathrm{kg} b w$ by a single intraperitoneal injection on the fourth day. At the end of the experiment, rats were anesthetized with $0.5 \mathrm{~mL}$ urethane $(40 \mathrm{mg} / \mathrm{mL})$ and sacrificed, their blood collected and processed for plasma and erythrocytes parameters using automates and biochemical determination of anti-oxidant status parameters.

\section{Blood processing}

Whole blood was obtained by cardiac puncture and collected into heparinized tubes. Erythrocytes were isolated from plasma by centrifugation at $1000 \mathrm{~g}$ for 10 min at $4^{\circ} \mathrm{C}$ and homogenized using a hypotonic buffer Tris- $\mathrm{HCl} 10$ mM pH 7.5, $\mathrm{MgCl}_{2} 5$ mM, NaCl 10 mM.

\section{Plasma and erythrocytes transaminases measurement}

Plasma and erythrocytes aspartate aminotransferase (AST) and alanine aminotransferase (ALT) were measured enzymatically using a commercial kit from Biomaghreb (Ariana, Tunisia) following the manufacturer's procedure (Reitmans and Frankels, 1957).

\section{Lipoperoxidation}

Lipoperoxidation was determined by malondialdehyde (MDA) measurement according to the double heating method (Draper and Hadley, 1990). Briefly, aliquots from erythrocyte homogenates or plasma were mixed with BHT-TCA solution containing 1\% BHT (m/v) dissolved in $20 \%$ TCA (m/v) and centrifuged at $1000 \mathrm{~g}$ for $5 \mathrm{~min}$ at $4^{\circ} \mathrm{C}$. The supernatant was blended with $0.5 \mathrm{~N} \mathrm{HCl}$, and $120 \mathrm{mM}$ TBA in $26 \mathrm{mM}$ Tris, and then heated at $80^{\circ} \mathrm{C}$ for $10 \mathrm{~min}$. After cooling, absorbance of the resulting chromophore was determined at $532 \mathrm{~nm}$ using a Bio-Rad UV-visible spectrophotometer. MDA levels were determined by using an extinction coefficient for MDA-TBA complex of $1.56105 \mathrm{M}-1 \mathrm{~cm}-1$.

\section{Protein carbonylation}

Oxidative damage to proteins was evaluated by quantifying protein carbonylation in red blood cells homogenates or plasma according to Levine et al. (1990). After protein were precipitated with $20 \%$ TCA and centrifuged at $x 11,000 \mathrm{~g}$ for $3 \mathrm{~min}$ at $4^{\circ} \mathrm{C}$ (Beckman J20), 
Bangladesh J Pharmacol 2012; 7: 54-62

the pellet was dissolved in $10 \mathrm{mM}$ DNPH-containing buffer. After 3 washes with ethanol- ethylacetate (1:1), the pellet was dissolved in $20 \mathrm{mM}$ potassium phosphate $(\mathrm{pH} 2.3)$ containing $6 \mathrm{M}$ guanidine chloride and absorbance measured at $366 \mathrm{~nm}$ using the molar extinction coefficient of $22000 \mathrm{M}-1 \mathrm{~cm}-1$. Results were expressed as nmol carbonyl residues/mg protein.

\section{Protein determination}

Total soluble proteins were determined according to the biuret method (Ohnishi and Barr, 1978). Briefly, at acidic $\mathrm{pH}$, soluble proteins constituted with copper a colourful complex measurable at $546 \mathrm{~nm}$ using a SmartSpec 3000 Bio-Rad UV-visible spectrophotometer (Germany).

\section{Anti-oxidant enzyme activity assays}

All spectrophotometric analyses of erythrocytes and plasma anti-oxidant enzyme activities were performed with a SmartSpec 3000 Bio-Rad UV-visible spectrophotometer (Germany).

Catalase (CAT) activity was assayed by measuring the initial rate of $\mathrm{H}_{2} \mathrm{O}_{2}$ disappearance at $240 \mathrm{~nm}$ (Aebi, 1984). The reaction mixture contained $33 \mathrm{mM} \mathrm{H}_{2} \mathrm{O}_{2}$ in 50 $\mathrm{mM}$ phosphate buffer ( $\mathrm{pH} 7.0)$ and erythrocytes extract or plasma. CAT activity was calculated using an extinction coefficient of $40 \mathrm{mM}-1 \mathrm{~cm}-1$ for $\mathrm{H}_{2} \mathrm{O}_{2}$.

Peroxidase (POD) activity was measured at $25^{\circ} \mathrm{C}$ using guaiacol as the hydrogen donor. The reaction mixture contained $9 \mathrm{mM}$ guaiacol, $19 \mathrm{mM} \mathrm{H}_{2} \mathrm{O}_{2}$ in $50 \mathrm{mM}$ phosphate buffer $\mathrm{pH} 7$ and erythrocytes extract or plasma in a final volume of $1 \mathrm{~mL}$. The reaction was initiated by the addition of $\mathrm{H}_{2} \mathrm{O}_{2}$ and monitored by measuring the increase in absorbance at $470 \mathrm{~nm}$ every $30 \mathrm{sec}$ for $3 \mathrm{~min}$. POD activity was expressed as nmol of guaiacol oxidized per min and calculated using a molecular extinction coefficient of $26.2 \mathrm{mM}-1$ (Chance and Maehly, 1955).

Superoxide dismutase (SOD) activity was determined by using a modified epinephrine assay (Misra and Fridovich, 1972). At alkaline $\mathrm{pH}$, superoxide anion $\left(\mathrm{O}_{2-}\right)$ causes the auto-oxidation of epinephrine to adrenochrome. One unit of SOD is defined as the amount of extract that inhibits the rate of adenochrome formation by $50 \%$. Enzyme extract was added to a $2 \mathrm{~mL}$ reaction mixture containing $10 \mu \mathrm{L}$ bovine catalase $(0.4 \mathrm{U} / \mu \mathrm{L}), 20$ $\mu \mathrm{L}$ epinephrine $(5 \mathrm{mg} / \mathrm{mL})$ and $62.5 \mathrm{mM}$ sodium carbonate-sodium bicarbonate buffer ( $\mathrm{pH}$ 10.2). Changes in absorbance were recorded at $480 \mathrm{~nm}$. Characterization of SOD isoforms was performed using $\mathrm{KCN}$ (3 mM), which inhibits $\mathrm{Cu} / \mathrm{Zn}-\mathrm{SOD}$ or $\mathrm{H}_{2} \mathrm{O}_{2}(5 \mathrm{mM})$, affecting both $\mathrm{Cu} / \mathrm{Zn}-\mathrm{SOD}$ and Fe-SOD. Mn-SOD was insensitive to both inhibitors.

\section{Free iron determination}

Erythrocytes and plasma free iron levels were deter- mined according to Leardi et al. (1998) using a commercially available kit from Biomaghreb. Briefly, at acidic $\mathrm{pH} 4.8$ all $\mathrm{Fe}^{3+}$ released from transferrin were reduced by ascorbic acid into $\mathrm{Fe}^{2+}$, which constitutes with ferrozine a purple colourful complex measurable at $560 \mathrm{~nm}$. Briefly, $50 \mu \mathrm{L}$ of erythrocytes extract or plasma was added to $250 \mu \mathrm{L}$ of reaction mixture containing ascorbic acid (5 g/L) and ferrozin (40 mM), and incubation was performed at $37^{\circ} \mathrm{C}$ for $10 \mathrm{~min}$.

\section{$\mathrm{H}_{2} \mathrm{O}_{2}$ determination}

Erythrocytes and plasma $\mathrm{H}_{2} \mathrm{O}_{2}$ levels were determined enzymatically according to Kakinuma et al. (1979) using a commercially available kit from Biomaghreb. Briefly, in the presence of POD, $\mathrm{H}_{2} \mathrm{O}_{2}$ reacts with 4-aminoantipyrine and phenol to give a red-colored quinoeimine that absorbs at $505 \mathrm{~nm}$. Results are expressed as mmol $\mathrm{H}_{2} \mathrm{O}_{2} / \mathrm{mg}$ protein.

\section{Calcium measurement}

Intracellular calcium was determined according to Stern and Lewis (1957) using a commercially available kit from Biomaghreb. At basic $\mathrm{pH}$, calcium constitutes with cresolphtalein a purple colorful complex measurable at $570 \mathrm{~nm}$. Briefly, $50 \mu \mathrm{L}$ of erythrocytes extract or plasma was added to $650 \mu \mathrm{L}$ of reaction mixture containing 2amino-2-methyl 1-propanol buffer (500 mmol/L), cresolphtalein $(0.62 \mathrm{mmol} / \mathrm{L})$, and hydroxy-8 quinoleine $(69 \mathrm{mmol} / \mathrm{L})$. Incubation was carried out at room temperature for $5 \mathrm{~min}$ assuming the complex was stable for 1 hour.

\section{Statistical analysis}

Data were analyzed by unpaired Student's t-tests or 1way analysis of variance (ANOVA) and expressed as means \pm standard error of the mean (SEM). All statistical tests were 2 -tailed, and results with a $p$ value $<0.05$ were considered significant.

\section{Results}

Figure 1 shows the effect of Dox and GSSE either alone or in combination on erythrocytes (Figure 1A) and plasma (Figure 1B) lipoperoxidation and on erythrocytes (Figure 1C) and plasma (Figure 1D) protein carbonylation. Dox increased erythrocytes and plasma lipoperoxidation and carbonylation, and GSSE, which had no significant effect per se, counteracted all Doxinduced deleterious effects. Noticeably that plasma MDA increased significantly over control when animals where co-treated with Dox and GSSE (Figure 1B).

Dox significantly decreased erythrocytes ALT (Figure 2A) and AST (Figure 2C) and increased plasma ALT (Figure 2B) and AST (Figure 2D). Treatment with GSSE counteracted all Dox-induced disturbances to near control level except erythrocytes AST which increased 


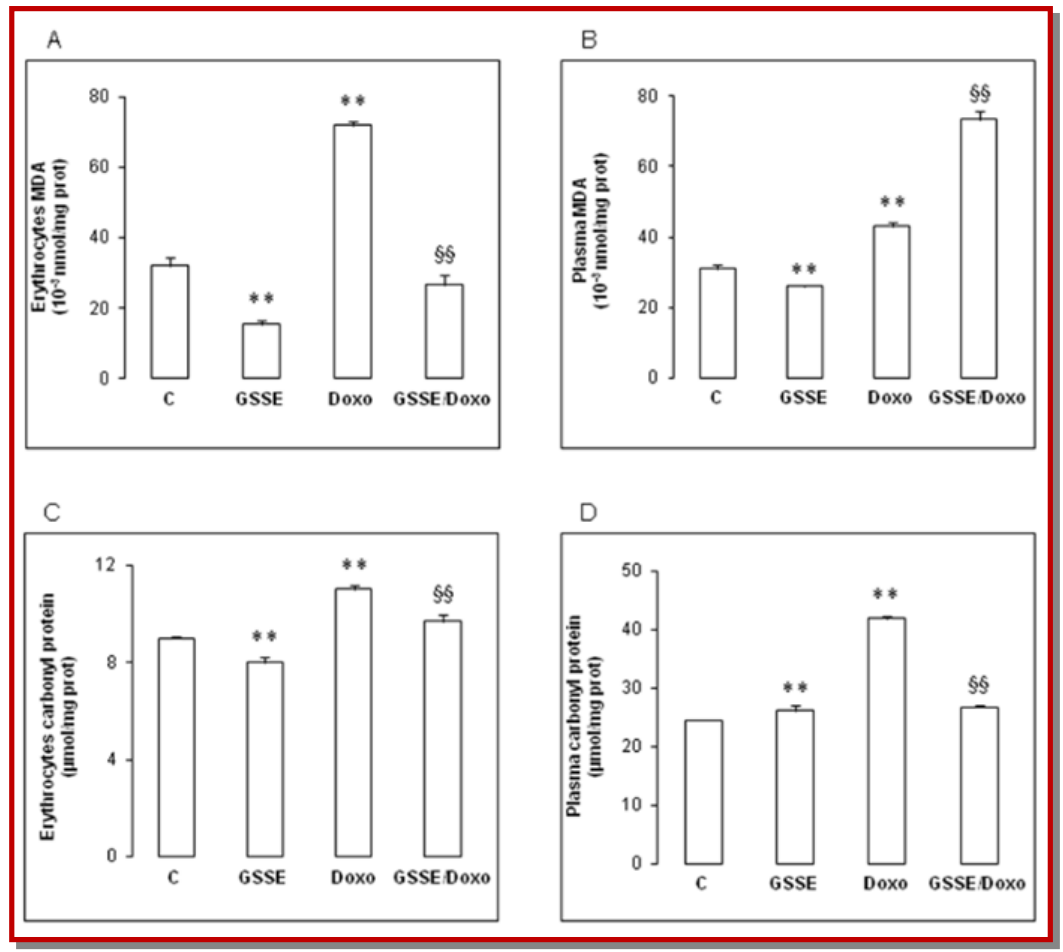

Figure 1: Effect of doxorubicin and GSSE on erythrocytes and plasma oxidation. Rats were pre-treated or not with GSSE during 8 days and challenged with a single dose of Dox at the fourth day. Erythrocytes (A) and plasma (B) MDA and erythrocytes (C) and plasma (D) protein carbonylation were determined. Results are expressed as mean $\pm S E M(n=6)$. ${ }^{* *} p<0.01$ vs $C$. $\S \S p<0.01$ vs Dox

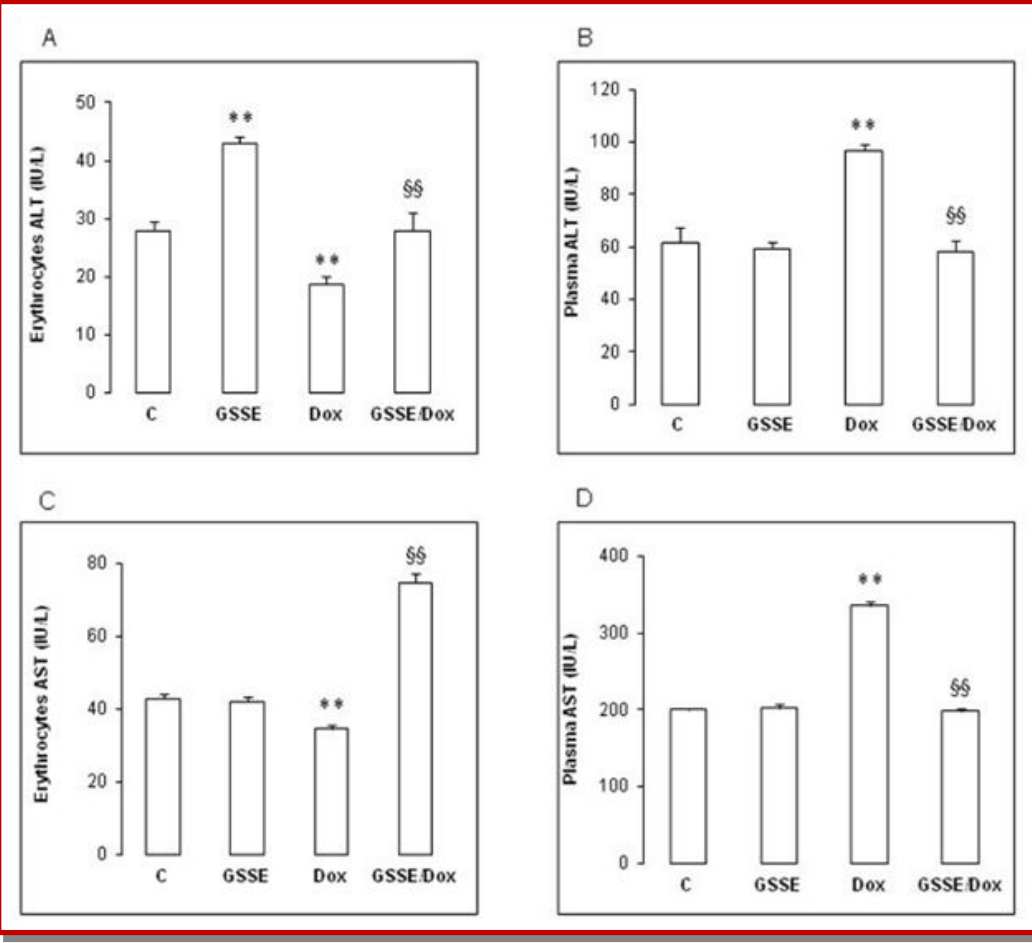

Figure 2: Effect of doxorubicin and GSSE on erythrocytes and plasma transaminases. Rats were pre-treated or not with GSSE for 8 days and challenged with a single dose of Dox at the fourth day. Erythrocytes (A) and plasma (B) ALT and erythrocytes (C) and plasma (D) AST were determined. Results are expressed as mean \pm SEM $(n=6) .{ }^{* *} p<0.01$ vs $C$. $\S \S p<0.01$ vs Dox 


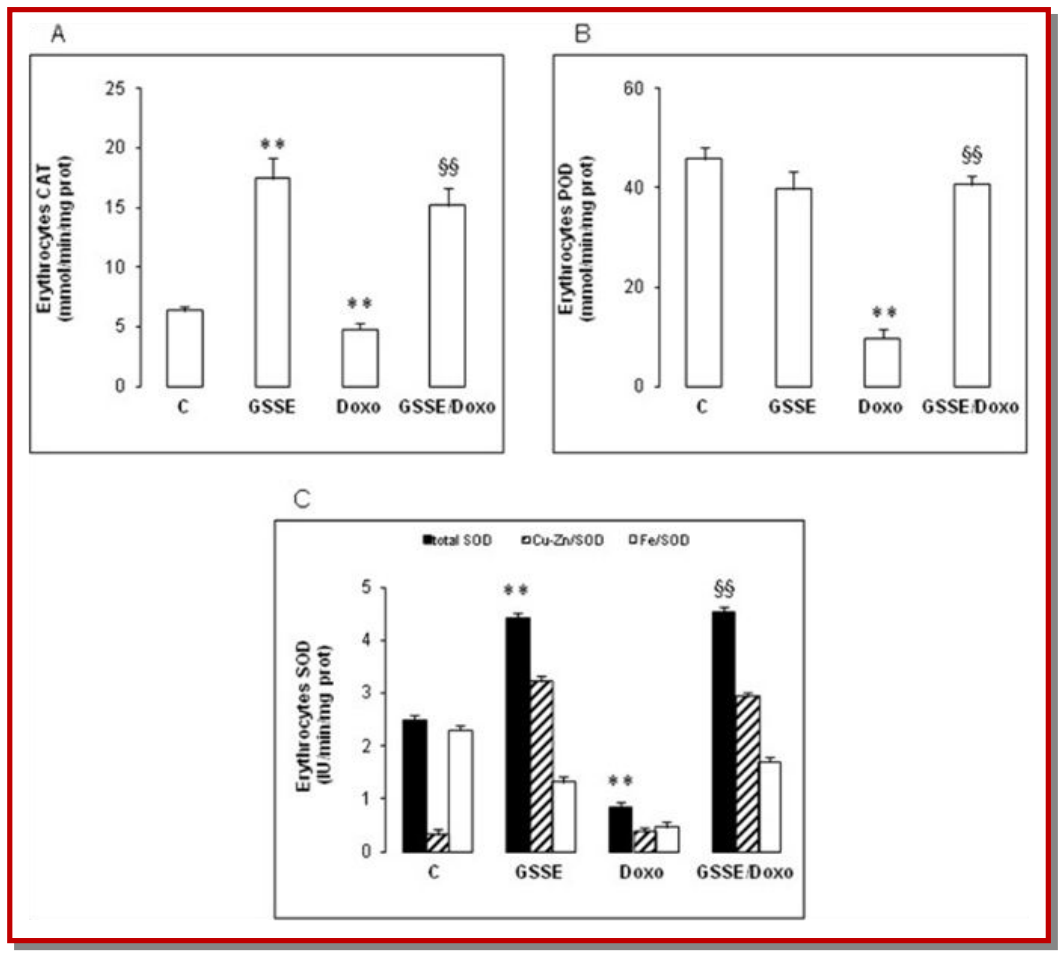

Figure 3: Effect of doxorubicin and GSSE on erythrocytes anti-oxidant enzyme activities. Rats were pre-treated or not with GSSE for 8 days and challenged with a single dose of Dox at the fourth day. Erythrocytes CAT (A), POD (B) and SOD (C) activities were determined. Results are expressed as mean $\pm \operatorname{SEM}(n=6)$. ${ }^{* *} p<0.01$ vs $C$. $\S \S p<0.01$ vs Dox

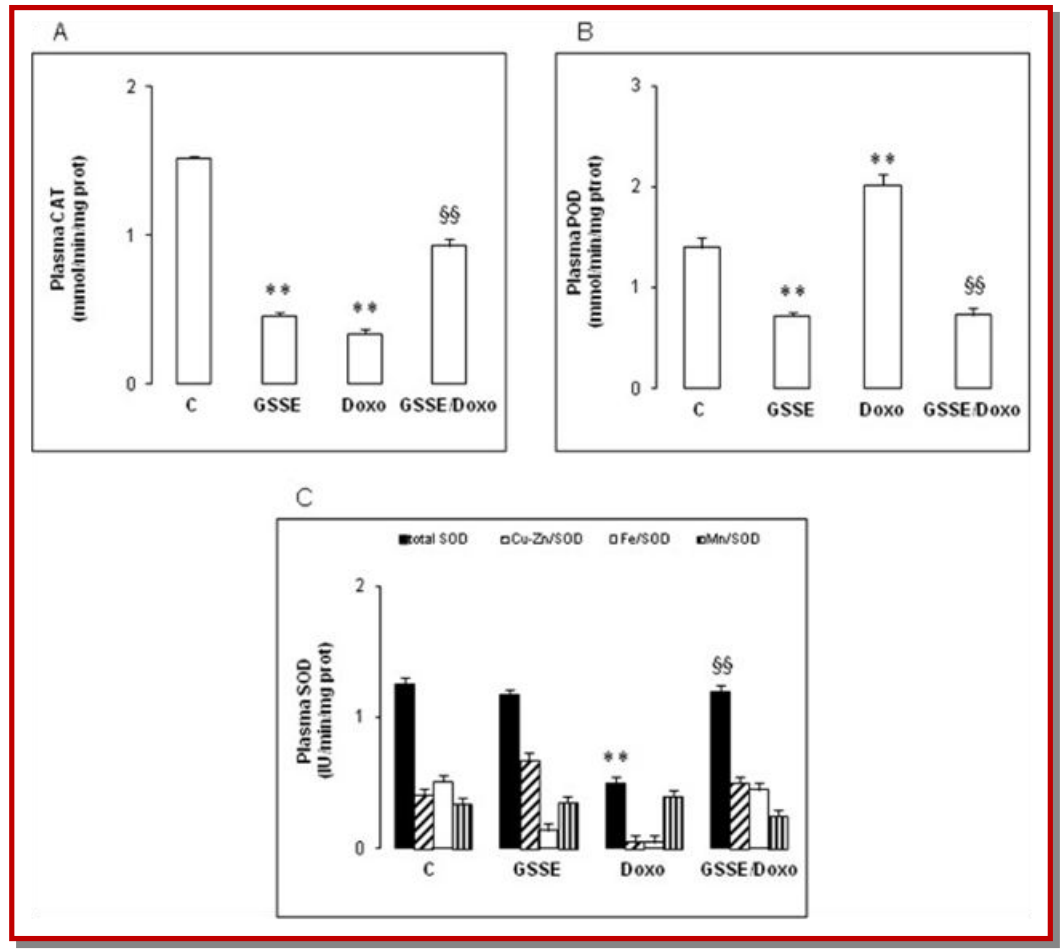

Figure 4: Effect of doxorubicin and GSSE on plasma anti-oxidant enzyme activities. Rats were pre-treated or not with GSSE for 8 days and challenged with a single dose of Dox at the fourth day. Plasma CAT (A), POD (B) and SOD (C) activities were determined. Results are expressed as mean $\pm \operatorname{SEM}(n=6) .{ }^{* *} \mathrm{p}<0.01$ vs $C$. $\S \S \mathrm{p}<0.01$ vs Dox 


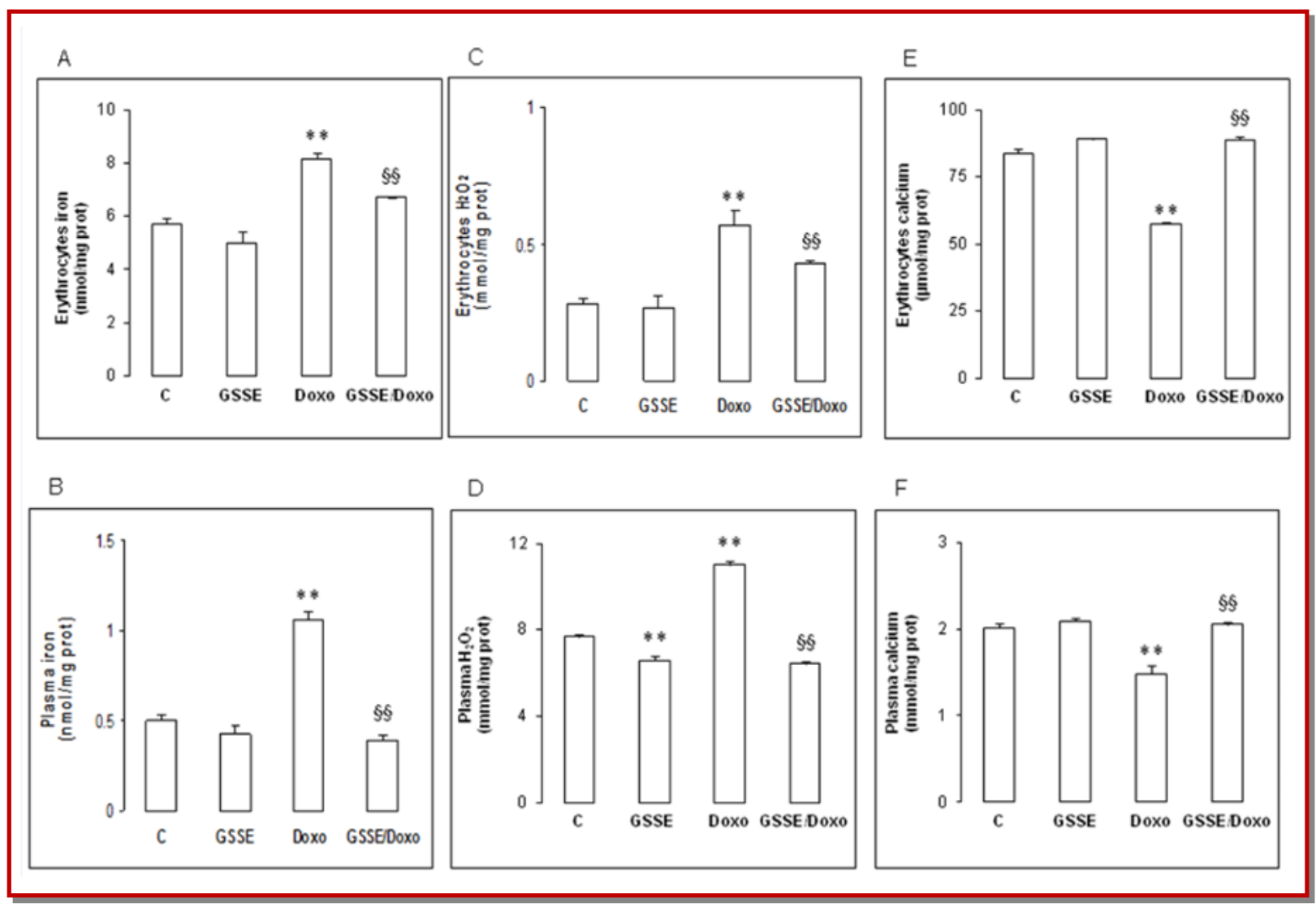

Figure 5: Effect of doxorubicin and GSSE on erythrocytes and plasma mediators

Rats were pre-treated or not with GSSE for 8 days and challenged with a single dose of Dox at the fourth day. Erythrocytes and plasma free iron (A, B), $\mathrm{H}_{2} \mathrm{O}_{2}(\mathrm{C}, \mathrm{D})$ and calcium (E, F) were determined. Results are expressed as mean $\pm \mathrm{SEM}(\mathrm{n}=6)$. ${ }^{* *} \mathrm{p}<0.01$ vs C. $\S \S p<0.01$ vs Dox.

significantly following Dox and GSSE co-treatment.

Dox treatment down-regulated CAT (Figure 3A), POD (Figure 3B) and SOD (Figure 3C) activity (Figure 3A). Remarkably that among SOD Dox mainly affected the Fe isoform. GSSE alone had no effect on POD, increased CAT and SOD activities and in this latter case, mainly affected the $\mathrm{Cu} / \mathrm{Zn}$ isoform. Importantly GSSE treatment counteracted all the deleterious effects of Dox on anti-oxidant enzyme activities to levels even higher than control i-e CAT and Cu/Zn-SOD isoform.

The effect of Dox on plasma anti-oxidant enzyme activities is reported in Figure 4. Dox negatively affected CAT and SOD activities and in this latter case mainly depressed the $\mathrm{Cu} / \mathrm{Zn}$ and Fe isoforms without affecting the Mn one. Pre-treatment with GSSE abrogated the Dox-induced disturbances in anti-oxidant enzyme activities to near control level.

We further sought to determine the putative involvement of intracellular mediators as $\mathrm{Ca}^{2+}$ in Dox-induced oxidative stress. In the same time, Dox increased free iron and $\mathrm{H}_{2} \mathrm{O}_{2}$ into erythrocytes and plasma and decreased free calcium. Once again, pre-treatment with
GSSE counteracted the Dox-induced blood disturbances of intracellular mediators.

\section{Discussion}

In the present study we analyzed the toxicity of Dox into the blood compartment. We found that Dox provoked a drastic oxidative stress status within erythrocytes and plasma as assessed by high MDA and carbonyl protein, elevated AST and ALT within plasma and a drastic depression of anti-oxidant enzymes in both compartments. Dox also increased free iron and $\mathrm{H}_{2} \mathrm{O}_{2}$, it likely induced the highly toxic hydroxyl radical which in turn affects $\mathrm{Ca}^{2+}$ homeostasis (Ishii et al., 2006) and ultimately lead to erythrocyte death and anaemia. Several previous studies have shown the implication of $\mathrm{Ca}^{2+}$ disturbances in Dox-induced cardiotoxicity (Lebrecht et al., 2009). However to our knowledge our data are the first to describe such a phenomenon into the blood compartment.

Furthermore Dox treatment depressed CAT, POD and SOD activities within erythrocytes. Among SOD activi- 
ties, the Fe-SOD was the only affected isoform, although we noticed in the same time that Dox increased both free iron and $\mathrm{H}_{2} \mathrm{O}_{2}$. Consequently Dox induced a drastic oxidative stress within erythrocytes that lead to hydroxyl radical generation which has been implicated in $\mathrm{H}_{2} \mathrm{O}_{2}$-induced calcium activation and cell death (Ishii et al., 2006). However in our present case we found Dox to depress erythrocyte $\mathrm{Ca}^{2+}$ (Jensen, 1986), whereas most studies described Dox-induced $\mathrm{Ca}^{2+}$ overloading (Kalivendi et al., 2005). Differential experimental conditions as Dox administration after a single high dose of $20 \mathrm{mg} / \mathrm{kg}$ could explain this discrepancy. Further studies should investigate which kind of calcium channels (L or T type) is involved in the mechanism of action of Dox using calcium channel modulators as verapamil or nifedipine.

Overall Dox-induced oxidative stress within erythrocytes appeared much more drastic than into the heart as demonstrated by some of us (Mokni et al., 2012). Because of the high polyunsaturated fatty acid content of their membranes and the high cellular concentration of oxygen, erythrocytes are highly susceptible to oxidative damage. Increased MDA level is known to affect the fluidity of the membrane lipid bilayer (Bryszewska et al., 1995) and high MDA level is generally correlated to stress-induced pathological conditions including aging (Rizvi and Maurya, 2007).

In our opinion, the most important result drawn from the present study is the ability of GSSE to prevent Doxinduced oxidative stress in rat erythrocytes and plasma compartment. GSSE is safe and devoid of any toxicity even at the high dosage used (Hebbar et al., 2005). GSSE protection could be mediated by ROS scavenging activity as demonstrated for resveratrol (Leonard et al., 2003).

GSSE extract is protective against cardiovascular diseases (Das and Maulik, 2006) and polyphenols containing GSSE as resveratrol and quercetin exerted anti-oxidant effects in human erythrocytes in vitro (Mikstacha et al., 2010). GSSE has been previously shown to protect multiple target organs from Dox (Mokni et al., 2012) and garlic-induced toxicity (Hamlaoui-Gasmi et al., 2012), owing to their anti-oxidant properties (Hamlaoui -Gasmi et al., 2011).

A possible mechanism by which GSSE could exert its beneficial effect on erythrocytes, is its ability to chelate free iron and to scavenge $\mathrm{H}_{2} \mathrm{O}_{2}$, re-establishing calcium homeostasis as recently found in rat heart subjected to a high fat regime (Charradi et al., 2011). Free iron is a well established catalyst of auto-oxidation and iron-mediated oxidations of cysteine residues represent a common mechanism through which $\mathrm{H}_{2} \mathrm{O}_{2}$ exerts its second messenger role in signal transduction pathways (Barbouti et al., 2007). Further studies should also analyze the implication of specific proteins involved in free iron metabolism as hepcidin (Isoda et al., 2010).
Moreover, $\mathrm{H}_{2} \mathrm{O}_{2}$ is able to induce dual roles in both survival and cell death pathways, largely depending on its concentration and also on the cell type. $\mathrm{H}_{2} \mathrm{O}_{2}$ exerted a prolongevity effect in several species including rat by induction of SOD activity (Yoshioka et al., 1994). GSSE could also exert its beneficial effects by its fatty acid moiety, having in mind the complex composition of GSSE (Khanal et al., 2009). Effective protection of blood cells could be achieved by some synergism between polyphenols and fatty acids containing GSSE. In this respect, fatty acids from magnolias seeds were recently shown to inhibit Dox-induced increase in intracellular $\mathrm{Ca}^{2+}$, ROS generation and apoptosis in rat cardiomyocytes (Park et al., 2008). Studies aiming at the identification of the bioactive components from GSSE responsible for the blood protection are in progress.

Another interesting feature of GSSE is its ability to increase erythrocyte CAT and SOD activities, more specifically the $\mathrm{Cu} / \mathrm{Zn}$ isoform in this latter case. Increased activity in anti-oxidant enzymes could correspond to post-translational modifications as phosphorylation inducing some gain of function as reported by Borchi et al. (2010) on human heart failure about increased CAT and GPx activities after tyrosine phosphorylation. In our case, GSSE could induce phosphorylation of CAT and $\mathrm{Cu} / \mathrm{Zn}-\mathrm{SOD}$ and by this way enhanced their activities without modifying their expression nor abundance. Moreover we can't exclude a positive effect of GSSE on $\mathrm{Cu}$ or $\mathrm{Zn}$ accumulation into erythrocytes leading to increased activity of the corresponding SOD isoform. Our present data are consistent with those of Danz et al. (2009) who showed cardioprotective effect of resveratrol against Dox- induced oxidative damage partly by its effect on $\mathrm{Mn}$ - SOD activity but not on protein expression.

\section{References}

Aebi H. Catalase in vitro. Methods Enzymol. 1984; 105: 121-26.

Barbouti A, Amorgianiotis C, Kolettas E, Kanavaros P, Galaris D. Hydrogen peroxide inhibits caspase-dependent apoptosis by inactivating procaspase- 9 in an iron-dependent manner. Free Rad Biol Med. 2007; 43: 1377-87.

Borchi E, Bargelli V, Stillitano F, Giordano C, Sebastiani M, Nassi PA, d'Amati G, Cerbai E, Nediani C. Enhanced ROS production By NADPH oxidase is correlated to changes in anti-oxidant enzyme activity in human heart failure. Biochim Biophys Acta. 2010; 1802: 331-38.

Bryszewska M, Zavodnik IB, Niekurzak A, Szosland K. Oxidative processes in red blood cells from normal and diabetic individuals. Biochem Mol Biol Int. 1995; 37: 345-54.

Buzdar AU, Marcus C, Smith TL, Blumenschein GR. Early and delayed clinical cardiotoxicity of doxorubicin. Cancer 1985; 55: 2761-65.

Chance B, Maehly AC. Assay of catalases and peroxidases. 
Methods Enzymol. 1955; 2: 764-817.

Charradi K, Sebai H, Elkahoui S, Ben Hassine F, Limam F, Aouani E. Grape seed extract alleviates high-fat dietinduced obesity and heart dysfunction by preventing cardiac siderosis. Cardiovasc Toxicol. 2011; 11:28-37.

Chatelain K, Phippen S, Mc Cabe J, Teeters CA, O'Malley S, Kingsley K. Cranberry and grape seed extracts inhibit the proliferative phenotype of oral squamous cell carcinomas. Evidence-Based Complement Altern Med. 2011; ID 467691. doi:10.1093/ecam/nen047.

Danz E, Skramsted J, Henry N, Bennett JA, Keller RS. Resveratrol prevents doxorubicin cardiotoxicity through mitochondrial stabilization and the Sirt1 pathway. Free Radic Biol Med. 2009; 46: 1589-97.

Das DK, Maulik N. Resveratrol in cardioprotection: A therapeutic promise of alternative medicine. Mol Interv. 2006; 6: 36-47.

Decordé K, Teissedre PL, Sutra T, Ventura E, Cristol JP, Rouanet JM. Chardonnay grape seed procyanidin extract supplementation prevents high-fat diet-induced obesity in hamsters by improving adipokine imbalance and oxidative stress markers. Mol Nutr Food Res. 2009; 53: 659-66.

Dewanto V, Wu X, Adom KK, Liu RH. Thermal processing enhances the nutritional value of tomatoes by increasing total anti-oxidant activity. J Agric Food Chem. 2002; 50: 301014 .

Doroshow JH, Locker GY, Myers CE. Enzymatic defenses of the mouse heart against reactive oxygen metabolites: Alterations produced by doxorubicin. J Clin Invest. 1980; 65: 128-35.

Draper HH, Hadley M. Malondialdehyde determination as index of lipid peroxidation. Methods Enzymol. 1990; 186: 421 -31 .

Dulundu E, Ozel Y, Topaloglu U, Toklu H, Ercan F, Gedik N, Sener G. Grape seed extract reduces oxidative stress and fibrosis in experimental biliary obstruction. J Gastroenterol Hepatol. 2007; 22: 885-92.

El-Ashmawy IM, Gad SB, Salama OM. Grape seed extract prevents azathioprine toxicity in rats. Phytother Res. 2010; 24: $1710-15$.

Hamlaoui-Gasmi S, Mokni M, Limam N, Limam F, Aouani E, Amri M, Marzouki L. Grape seed extract mitigates garlicinduced oxidative stress in rat spleen and plasma. J Med Plants Res. 2011; 5: 6076-84.

Hamlaoui-Gasmi S, Mokni M, Limam N, Limam F, Aouani E, Amri M, Marzouki L. Grape seed and skin extract mitigates garlic-induced oxidative stress in rat liver. Can J Pharm Pharmacol. 2012; 90: 547-56.

Hebbar V, Shen G, Hu R, Kim BR, Chen C, Korytko PJ, Crowell JA, Levine BS, Kong A-NT. Toxicogenomics of resveratrol in rat liver. Life Sci. 2005; 76: 2299-2314.

Ishii K, Tamaoka A, Takeda T, Ishii K, Iwasaki N, Shoji S. Clinical and neurological features of organoarsenic compound (diphenylarsenic acid) intoxication in Kamisu. Japan Rinsho Shinkeigaku. 2006; 46: 768.
Isodaa $\mathrm{M}$, Hanawab $\mathrm{H}$, Watanabeb $\mathrm{R}$, Yoshida $\mathrm{T}$, Toba $\mathrm{K}$, Yoshida K, Kojima M, Otaki K, Hao K, Ding L, Tanaka K, Takayama T, Kato K, Okura Y, Kodama M, Ota Y, Hayashi J, Aizawa Y. Expression of the peptide hormone hepcidin increases in cardiomyocytes under myocarditis and myocardial infarction. J Nutr Biochem. 2010; 21: 749-56.

Jensen RA. Doxorubicin cardiotoxicity: Contractile changes after long-term treatment in the rat. J Pharmacol Exper Ther. 1986; 236: 197-203.

Jiménez-Aliaga K, Bermejo-Bescós P, Benedí J, Martín-Aragón $\mathrm{S}$ Quercetin and rutin exhibit antiamyloidogenic and fibrildisaggregating effects in vitro and potent anti-oxidant activity in APPswe cells. Life Sci. 2011; 89:939-45.

Kakinuma K, Yamaguchi T, Kaneda M, Shimada K, Tomita $\mathrm{Y}$, Chance B. A determination of $\mathrm{H}_{2} \mathrm{O}_{2}$ release by the treatment of human blood polymorphonuclear leukocytes with myristate. J Biochem. 1979; 86: 87-95.

Kalivendi SV, Konorev EA, Cunnigham S, Vanamala SK, Kaji EH, Joseph J, Kalyanaraman B. Doxorubicin activates nuclear factor of activated T. lymphocytes and Fas ligand transcription: Role of mitochondrial reactive oxygen species and calcium. Biochem J. 2005; 389:527-39.

Kaur M, Mandair R, Agarwal R, Agarwal C. Grape seed extract induces cell cycle arrest and apoptosis in human colon carcinoma cells. Nutr Cancer. 2008; 60: 2-11.

Kelen M, Tepe B. Screening of anti-oxidative properties and total phenolic compounds of various extracts of three different seed of grape varieties (Vitis vinifera L.) from Turkish flora. Pak J Biol Sci. 2007; 10: 403-08.

Khanal RC, Howard LR, Prior RL. Procyanidin content of grape seed and pomace, and total anthocyanin content of grape pomace as affected by extrusion processing. J Food Sci. 2009; 74: H174-82.

Kowalczyk MC, Kowalczyk P, Tolstykh O, Hanausek M, Walaszek Z, Slaga TJ. Synergistic effects of combined phytochemicals and skin cancer prevention in SENCAR mice. Cancer Prev Res (Phila). 2010; 3: 170-78.

Leardi A, Caraglia M, Selleri C, Pepe S, Pizzi C, Notaro R, Fabbrocini A, De Lorenzo S, Musicò M, Abbruzzese A, Bianco AR, Tagliaferri P. Desferioxamine increases iron depletion and apoptosis induced by ara-C of human myeloid leukaemic cells. Brit J Haematol. 1998; 102: 746-52.

Lebrecht D, Kirschner J, Geist A, Haberstrah J, Walker UA. Respiratory chain deficiency precedes the disrupted calcium homeostasis in chronic doxorubicin cardio myopathy. Cardiovasc Pathol. 2009; 19: 167-74.

Leonard SS, Xia C, Jiang BH, Stinefelt B, Klandorf H, Harris GK, Shi X. Resveratrol scavenges reactive oxygen species and effects radical-induced cellular responses. Biochem Bioph Res Co. 2003; 309: 1017-26.

Levine LR, Garland D, Oliver CN, Amici A, Climent I, Lenz AG, Ahn BW, Shaltiel S, Stadtman ER. Determination of carbonyl content in oxidatively modified proteins. Method Enzymol. 1990; 186: 464-78.

Mikstacka R, Rimando AM, Ignatowicz E. Anti-oxidant effect of transresveratrol, pterostilbene, quercetin and their 
combinations in human erythrocytes in vitro. Plant Foods Hum Nutr. 2010; 65: 57-63.

Misra HP, Fridovich I. The role of superoxide anion in autoxidation of epinephrine and a simple assay for SOD. J Biol Chem. 1972; 247: 3170-75.

Mokni M, Hamlaoui-Guesmi S, Amri M, Marzouki L, Limam F, Aouani E. Grape seed and skin extract protects against acute chemotherapy toxicity induced by doxorubicin in rat heart. Cardiovasc Toxicol. 2012; 2012

National Research Council. Guide for the care and the use of laboratory animals. National institute of health, Bethesda. 1985; 20: 85-123.

Ngamukote S, Mäkynen K, Thilawech T, Adisakwattana S. Cholesterol-lowering activity of the major polyphenols in grape seed. Molecules 2011; 16: 5054-61.

Ohnishi ST, Barr JK. A simple method of quantitating protein using the biuret and phenol reagent. Anal Biochem. 1978; 86: $193-200$.

Park KH, Kim SY, Gul R, Kim BJ, Jang KY, Chung HT, Sohn DH. Fatty acids ameliorate doxorubicin-induced intracellular calcium increase and apoptosis in rat cardiomyocytes. Biol Pharm Bull. 2008; 31: 809-15.

Reitman S, Frankel S. A colorimetric method for the determination of serum glutamic oxalacetic and glutamic pyruvic transaminases. Am J Clin Pathol. 1957; 28: 56-63.

Renaud S, De Lorgeril M. Wine, alcohol, platelets, and the French paradox for coronary heart disease. Lancet. 1992; 339 (8808): 1523-26.

Rizvi SI, Maurya PK. Markers of oxidative stress in erythrocytes during aging in humans. Ann NY Acad Sci. 2007; 1100: $373-82$.

Rosen GM, Halpern HJ. Spin trapping biologically generated free radicals: Correlating formation with cellular injury. Method Enzymol. 1990; 18: 611-21.

Safa J, Argani H, Bastani B, Nezami N, Ardebili BR, Ghorbanihaghjo A. Protective effect of grape seed extract on gentamicin-induced acute kidney injury. Iran J Kid Dis. 2010; 4: 285-91.

Sehirli O, Ozel Y, Dulundu E, Topaloglu U, Ercan F, Sener G. Grape seed extract treatment reduces hepatic ischemia- reperfusion injury in rats. Phytother Res. 2008; 22: 43-48.

Singal PK, Deally CM, Weinberg LE. Subcellular effects of adriamycin in the heart: A concise review. J Mol Cell Cardiol. 1987; 19: 817-28.

Singal PK, Iliskovic N. Doxorubicin-induced cardiomyopathy. New Engl J Med. 1998; 339: 900-05.

Singal PK, Siveski-Iliskovic N, Hill M, Thomas TP, Li T. Combination therapy with probucol prevents adriamycininduced cardiomyopathy. J Mol Cell Cardiol. 1995; 27: 105563.

Singleton VL, Rossi JA. Colorimetry of total phenolic with phosphomolybdic-phosphotungstic acid reagent. Am J Enol Vitic. 1965; 16: 144-58.

Sinha BK, Katki AG, Batist G, Cowan KH, Myers CE. Adriamycin stimulated hydroxyl radical formation in human breast tumor cells. Biochem Pharmacol. 1987a; 36: 793-96.

Sinha BK, Katki AG, Batist G, Cowan KH, Myers CE. Differential formation of hydroxyl radicals by adriamycin in sensitive and resistant MCF-7 human breast tumor cells: Implications for the mechanism of action. Biochemistry 1987b; 26: 3776-81.

Stern J, Lewis WH. The colorimetric estimation of calcium in serum with ocresolphthalein complexone. Clin Chim Acta. 1957; 2: 576-80.

Sun BS, Ricardo-Da-Silva JM, Spranger MI. Critical factors of vanillin assay for catechins and proanthocyanidins. J Agric Food Chem. 1998; 46: 4267-74.

Suwannaphet W, Meeprom A, Yibchok-Anun S, Adisakwattana S. Preventive effect of GSE against high fructose diet-induced insulin resistance and oxidative stress in rats. Food Chem Toxicol. 2010; 48: 1853-57.

Wang YJ, Thomas P, Zhong JH, Bi FF, Kosaraju S, Pollard A, Fenech M, Zhou XF. Consumption of grape seed extract prevents amyloïd-â deposition and attenuates inflammation in brain of an Alzheimer's disease mouse. Neurotox Res. 2009; 15: 3-14

Yoshioka T, Homma T, Meyrick B, Takeda M, Moore-Jarett T, Kon V, Ichikawa I. Oxidants induce transcriptional activation of manganese superoxide dismutase in glomerular cells. Kidney Int. 1994; 46: 405-13. 